\title{
Amplifiers in International Journal Articles Ten Years on and Now
}

\author{
Almira Fidela Artha, Universitas Airlangga
}

\begin{abstract}
In the last ten years on, amplifier in academic prose has been formulated by Biber et. al (1999). This study tends to compare amplifier by Biber et. al (1999) with current circumstance in international journal articles. This study used a corpus taken from 400 -journal articles published by Elsevier across science disciplines i.e., social sciences, health sciences, life sciences, and physical sciences. The finding exclusively shows that the academic prose specifically in the international journal article usually uses so, very, highly, strongly, clearly, fully, potentially, statistically, too, quite, completely, entirely and extremely as a vehicle to influence reader's reception. In contrast, in the last ten years, Biber et al. (1999) argue that the most common amplifiers in academic prose are very, so, too, extremely, highly, completely, entirely, and fully. According to those findings, it can be summarized that language is fluid, and amplifier adverb is slightly shifted from ten years on to current years. Moreover, these results are also expected to assist students, and teachers to be able influencing reader's perception by using amplifiers in their academic writing.
\end{abstract}

Keywords: amplifier/intensifier adverb; four-science disciplines; international journal articles

\section{Introduction}

All of the texts both written and spoken text always contains a small mode of expressive devices. These expressive devices usually werecalled as amplifier (Quirk, 1985; Biber et. al., 1999; Hinkel, 2003) or intensifier (Pérez-Paredes \& Díez-Bedmar, 2012). Partington (1993) describes that amplifier is a vehicle for impressing, praising, persuading, insulting, and generally influencing the listener's reception of the message. Therefore, it can be summarized that amplifier/intensifier is important to exploit hyperbole in any genre text, emphasize messages, and convey meaning both spoken orwritten text (i.e., conversation, academic prose, news, or fiction).

Amplifier/intensifier in text can be reflected in adverb of quality, adjective or verb (De Devitiis, Mariani, \& O'Malley, 1989). However, amplifier/intensifier in academic prose is important but rarely being used and uneven. Amplifier/intensifier found more frequently in spoken text (i.e.,conversational discourse), but rarely occur in academic prose (Biber et al., 1999). Philip (2008) also found that amplifier/intensifier especially intensifying adverb are problematic for learner since the learner tends to over-used same intensifying adverb (i.e: quite, very, and really), but rarely used other intensifying adverb (i.e., highly, deeply). The usage of intensifying adverb isalso problematic for EFL across nations, as Pérez-Paredes (2010) found that intensifying adverbs are a problem for Dutch, French, Italian, Spanish, and German young adult learners of English.

Schmitt (2010) suggests that EFL does not need to achieve native-like vocabulary sizes in order to use English well. EFL students should be better to learn some measurable, necessary and reasonable vocabulary to understand variousEnglish communication forms. In this case, amplifier/intensifier in academic prose is unarguably important to me measured. Although amplifier/intensifier adverbs are discussed in many studies (i.e., Biber et.al., 1999; Hinkel, Journal of Pragmatics; Pérez-Paredes \& Díez-Bedmar, 2012), none of the research related common amplifier/intensifier adverb in journal article of four science disciplines in order to assist academic writing in makinghyperbolic statement. Therefore, this research aims to figure out current amplifier/intensifier adverb in academic journal article and compare it into amplifier/intensifier of academic prose based onBiber et al., (1999). 


\section{Method}

The corpus in this study is derived from international journal article by Elsevier. Elsevier was chosen as one of the top three of academic publishing houses of journals and books (Chatterton \& Maxey, 2009). The corpus data were classified based on Elsevier's classification of four science disciplines (i.e., social sciences, health sciences, life sciences, and physical sciences). To retain the corpus data "academic only", there are several criteria were set. First, the journal selected must be open access journal. Second, the journal shouldhave impact factor. Third, the year publication is around 2010-2015. Forth, the journal article is in form of English journal based. In compiling the corpus, 100 articles for each science disciplines were selected. The final corpus data in this study are 400 journal articles or 2.954 .587 word tokens were processed to figure out the amplifier/intensifier adverb in academic journal article (See Table 1).

Table 1: Corpus data Distributions

\begin{tabular}{|l|l|l|}
\hline $\begin{array}{l}\text { Science } \\
\text { Disciplines }\end{array}$ & $\begin{array}{l}\text { Number of } \\
\text { Articles }\end{array}$ & Word Tokens \\
\hline Health Sciences & 100 & 467.549 \\
\hline Life Sciences & 100 & 672.202 \\
\hline Physical Sciences & 100 & 892.680 \\
\hline Social Science & 100 & 922.156 \\
\hline Total & 400 & 2.954 .587 \\
\hline
\end{tabular}

\section{Finding}

To figure out the amplifier/intensifier adverb, several steps were being followed. First, the software called AntConc (Anthony, 2014) is utilized. AntConc (Anthony, 2014) is used to extract the word list with their frequencies. In this processed, words with minimum frequencies of 100 were selected, and 3489 wordswere found. Second, in order to extract the adverb, those 3489 word lists were processedin CLAWSTagger, in which can be accessed in http://ucrel.lancs.ac.uk/claws/trial.html (Rayson). As the results, 155 adverbs weremined from CLAW Tagger. Third, the adverb of quality or the amplifier/intensifier adverb was selected manually.

The final amplifier/intensifier adverbs in this international journal article are only 13 words, those are: so, very, highly, strongly, clearly, fully, potentially, statistically, too, quite, entirely, completely, and extremely.In contrast, in the last ten years, Biber et. al. (1999) argue that the most common amplifiers in academic prose are very, so, too, quite, extremely, highly, completely, entirely, and fully. The finding shows that some of amplifier/intensifier from 1999 are slightly shifted in which can be seen in Table 2 (See Table 2).

Table 2: Amplifier/intensifier Ten Years on and Now

\begin{tabular}{|c|l|c|l|}
\hline \multicolumn{4}{|c|}{ Amplifier/intensifier Distributions } \\
\hline No & $\begin{array}{c}\text { Both Biber et al. (1999) and } \\
\text { Current Research }\end{array}$ & $\begin{array}{c}\text { In Biber et al. } \\
(\mathbf{1 9 9 9 )} \text { only }\end{array}$ & $\begin{array}{c}\text { In this Current } \\
\text { Research only }\end{array}$ \\
\hline 1 & Very & - & Strongly \\
\hline 2 & So & & Clearly \\
\hline 3 & Too & & Potentially \\
\hline 4 & Quite & & Statistically \\
\hline 5 & Extremely & & \\
\hline 6 & Highly & & \\
\hline 7 & Completely & & \\
\hline 8 & Fully & & \\
\hline 9 & Entirely & \\
\hline
\end{tabular}


According to Table 2, there are 8 amplifier/intensifier adverbs are constant from 1999 to 2018, those are very, so, too, quite, extremely, highly, completely, and fully. Thatamplifier/intensifier can be considered as common amplifier/intensifier adverb or general amplifier/intensifier adverb in academic prose. Biber et al. (1999) established that very, so, and too are common amplifier/intensifier adverb in academic prose.Moreover, so is also highly used in current journal articles and makes up about 2030 hits. Veryis also highly obtained, and makes up about 1354 hits. In contrast, toosurprisingly only has 309 hits. Several collocates of too in this journal article are small (21), much (17), high (13), large(21), and many (10). Biber et al. (1999) argue that too is describing the degree of a characteristic as excessive relative to the requirements of a particular set of circumstances (See Figure 1).

Figure 1: The examples of too usage in International journal articles

$$
\begin{aligned}
& \text { caseecontrol sample sizes studied to date are too small to detect particularly small-effect risk } \\
& \text { compliance, reported a sample size that was too small to draw any definite conclusions.29 The } \\
& \text { is lost because the photon energy is too small to excite the absorber ( } \mathrm{E}<\mathrm{Eg} \text { ), } \\
& \text {, even then the cross section limits are too small to explain any of the proposed } \\
& \text { the precision of the experiment and were too small to have clinical relevance. Tibial Exter } \\
& \text { symbols. Glass spheres that would have been too small to have retained at least } 90 \% \text { of } \\
& \text { boxes. Glass shards that would have been too small to have retained at least } 90 \% \text { of } \\
& \text { rates. This is because the animals are too small to inject with weighed quantities of } \\
& \text { number the population of each cluster becomes too small to make meaningful comparisons. For the }
\end{aligned}
$$

The rest words such as quite, extremely, highly, completely, and fully are also included in Hinkel (2003) amplifier's formulations as scalar lexical intensity. The example of the usage of extremely and highly as scalar lexical intensity can be seen in the examples 1 and 2 below :

\begin{tabular}{|l|l|l|l|l|l|}
\hline 1 & $\begin{array}{l}\text { phosphoric acids, perhaps, so } \\
\text { this control is }\end{array}$ & extremely & difficult & $\begin{array}{l}\text { if not at times } \\
\text { impossible }\end{array}$ & H0161 \\
\hline 2 & $\begin{array}{l}\text { the response of the material } \\
\text { is }\end{array}$ & highly & sensitive & to fornix lesions & P0133 \\
\hline
\end{tabular}

The functions of extremely and highly in example 1 and 2 are to stress the scalar lexical intensity of the adjective (i.e.,difficult, and sensitive). The words extremely and highly absolutely givean emotive impact of adjective. In example 1, it says, "phosphoric acids, perhaps, so this control isextremely difficult if not at times impossible". The amplifier/intensifier extremely tends to strength the difficulties in controlling phosphoric acids in health science disciplines.

In fact, amplifier/intensifier adverb found in current research slightly more complex. There are four amplifier/intensifier adverb only found in this research, and it is absent in Biber, et. al. (1999). The amplifier/intensifier adverbs were statistically only found in this current research, such as strongly, clearly, potentially, and statistically (See Table 3).

Table 3. Amplifier/intensifier adverb only found in this current study

\begin{tabular}{|l|l|l|l|}
\hline No & $\begin{array}{l}\text { Amplifier/intensifier } \\
\text { Adverb }\end{array}$ & Frequency & Collocation \\
\hline $\mathbf{1}$ & Strongly & 465 & Agree (40), associated (20) \\
\hline $\mathbf{2}$ & Clearly & 423 & Demonstrate (21), show (11) \\
\hline $\mathbf{3}$ & Potentially & 382 & Important (13) \\
\hline $\mathbf{4}$ & Statistically & 362 & Significant (259), insignificant (13) \\
\hline
\end{tabular}


According to Table 3, the highest frequency amplifier/intensifier adverb only found in this current study are strongly (465), clearly (423), potentially (283), and statistically (362). Different with potentially and statistically as scalar lexical intensity of the adjective, strongly and clearly are scalar lexical intensity of the verb. Strongly commonly used to strength verb such as agree, and demonstrate. Meanwhile, clearly usually used to emphasize verb such as demonstrate and show.

\section{Conclusion}

According to those findings, it can be summarized that language is fluid, and amplifier adverb is slightly shifted from ten years on to current years. Amplifier/intensifier in academic writing is totally important in stressing, impressing, praising, persuading, insulting, and influencing the academician's reception of the message. Therefore, a research related amplifier/intensifierneed to be explored and monitored deeply. By composing amplifier/intensifier adverb is expected to be able assisting students, and teachers in their academic writing.

\section{References}

Anthony, L. 2014. AntWordProfiler (Version 3.5.7) [Computer Software]. Tokyo, Japan: Waseda University. Available at http://www.laurenceanthony.net/

Biber, D., Johansson, S., Leech, G., Conrad, S., Finegan, E., \& Quirk, R. 1999. Longman grammar of spoken and written English. London: Longman.

Chatterton, P., \& Maxey, L. 2009. Introduction: Whatever happened to ethics and responsibility in geography? ACME, 8(3), 429-439.

De Devitiis, G., Mariani, K., \& O’Malley, K. 1989. English grammar for communication. Harlow: Longman Group.

Hinkel, E. 2003. Adverbial markers and tone in L1 and L2 students' writing. Journal of Pragmatics, 1049-1068.

Partington, A. 1993. Corpus evidence of language change: The case of the. In M. Baker, G. Francis, \& E. Togninibonelli, Text and Technology. Amsterdam: John Benjamins, 177192.

Pérez-Paredes, P. 2010. In M. Jaén, F. Valverde, \& M. Pérez, Exploring new paths in language pedagogy lexis and corpus based language teaching. London: Equinox Publishing, 157172.

Pérez-Paredes, P., \& Díez-Bedmar, M. B. 2012. The Use of Intensifying Adverbs in Learner Writing. In Y. K. Y. Tono, Y. Tono, Y. Kawaguchi, \& M. Minegishi. London: John Benjamins, 105-122.

Philip, G. 2008. Adverb use in EFL student writing: From learner dictionary to text production. Proceedings of EURALEX XIII International lexicography congress. EURALEX .

Quirk, R. G. 1985. A comprehensive grammar of the english language. London: Longman.

Rayson, P. (s.d.). Free CLAWS WWW tagger Lancaster University [Computer Software]. Available athttp://ucrel.lancs.ac.uk/claws/trial.html

Schmitt, N. 2010. Researching vocabulary: A vocabulary research manual. New York: Palgrave Macmillan. 